\title{
OS DESAFIOS PARA AS MICRO E PEQUENAS EMPRESAS NO BRASIL COM A HARMONIZAÇÃO CONTÁBIL INTERNACIONAL: UM ESTUDO DE CASO SOBRE MORTUGABA
}

\author{
THE CHALLENGES FOR MICRO AND SMALL ENTERPRISES IN \\ BRAZIL WITH THE HARMONISATION INTERNATIONAL \\ ACCOUNTING: A CASE STUDY ON MORTUGABA
}

Data do recebimento do artigo: 13/05/2013

Data do aceite do artigo: 01/09/2013

Data da publicação: $2 / 12 / 2013$

\author{
Monara Souza de Castro ${ }^{1}$ \\ Graduada em Ciências Contábeis \\ Pontifícia Universidade Católica de São Paulo \\ Fernando de Almeida Santos \\ Doutor em Ciências Sociais \\ Mestre em Administração \\ Professor da Faculdade ENIAC
}

Professor da Pontifícia Universidade Católica de São Paulo

Professor do Mestrado do Centro Universitário das Faculdades Metropolitanas Unidas

\section{RESUMO}

O objetivo do trabalho é demonstrar as dificuldades de realizar a contabilização das empresas na Cidade de Mortugaba, devido à falta de profissionais qualificados, principalmente para as empresas de pequenos e médio porte. Com isso, descrever as condições em que a contabilidade é realizada, em uma cidade de interior, onde o acesso a informações e tecnologias são ainda remotas e conhecer limitações e a forma de acesso a informações contábeis e tecnológicas usadas para aplicar a Contabilidade.O trabalho consiste em uma pesquisa dedutiva, que utiliza de pesquisa bibliográfica, relato histórico e estudo de caso. $\mathrm{O}$ corpo do trabalho aborda a profissão do contador, as demonstrações contábeis e a NBC TG 1000 e estudo de caso sobre Mortugaba, cidade do interior da Bahia. Depois de ver duas situações exemplo no estudo de caso, pode-se ter uma breve visão de como a Contabilidade é conhecida e tratada pelos micro e pequenos empresários em uma cidade do interior do Brasil. As dificuldades geográficas, regionais e culturais também são responsáveis por tal fato. No caso específico abordado em Mortugaba, nota-se que a Contabilidade é pouco utilizada pela administração das empresas para o processo de decisão. Diante de tal dificuldade, nota-se a necessidade para que o Governo Federal repensar políticas públicas de estruturação trazendo

\footnotetext{
1 Autor para correspondência: Pontifícia Universidade Católica de São Paulo - R. Monte Alegre, 984 - Perdizes, São Paulo - SP,Brasil - 05014-901
} 
novas formas de capacitação e formação para futuros contadores. Sendo esse um passo inicial para a implantação da TG 1.000 em todo o País.

Palavras-Chave: Ciências Contábeis; Formação; Pequena e Média Empresa; Mortugaba; NBC TG 1000.

\begin{abstract}
The aim of this work is to demonstrate the difficulties of carrying out the company business accounting in the City of Mortugaba, due to lack of qualified professionals, especially for small and medium-sized companies, with that, to describe the conditions in which accounting is carried out in an inner city, where access to information and technology is still remote and to know limitations and the way of accessing the accounting and technological information used in order to apply accounting. The work consists of a deductive research, using bibliographical research, history report and a case study. The body of the work addresses the accounting profession, the accounting statements, the NBC TG - 1000 and case study of Mortugaba, inland town of Bahia. After seeing two example situations in the case study, It was possible to have a short view of how accounting is known and treated by micro and small entrepreneurs in a country city of Brazil. The geographical, regional and cultural difficulties are also responsible for such fact. At the specific case addressed in Mortugaba, it's possible to notice that Accounting is little used by the company management for the decision process. Faced with this difficulty, there is the need for the Federal Government to rethink structure public policy, bringing new ways of training and education for future accountants as an initial step toward the deployment of TG 1.000 around the country.
\end{abstract}

Keywords: Accounting; Training; Small and Medium-sized enterprise; Mortugaba; NBC TG 1000. 


\section{INTRODUÇÃO}

O Conselho Federal de Contabilidade, alinhando a Contabilidade à Harmonização Internacional, que busca o desenvolvimento global e local, por meio da Resolução CFC No. 1.255/09, aprovou a NBC TG 1000 (ex NBC - T - 19.41) que normatiza a Contabilidade para Pequenas e Médias Empresas. Esta Norma entrou em vigor no dia $1^{\circ}$ de Janeiro de 2010, e passou a ser obrigatória em $1^{\circ}$ de janeiro de 2012.

Tal norma é fundamental para a transparência e obriga as empresas enquadradas neste porte, a elaborarem as demonstrações contábeis.

Para exemplificar a dificuldade de elaboração das demonstrações, o trabalho analisa o interior da Bahia e o desenvolvimento regional e realiza um estudo de caso sobre o comércio em Mortugaba.

A pesquisa demonstra as dificuldades de realizar a contabilização das empresas na Cidade de Mortugaba, devido a falta de profissionais qualificados, principalmente para as empresas de pequenos e médio porte.

Os objetivos específicos do trabalho são:

- Descrever as condições em que a contabilidade é realizada, em uma cidade de interior, onde o acesso a informações e tecnologias são ainda remotas.

- Conhecer limitações e a forma de acesso a informações contábeis e tecnológicas usadas para aplicar a contabilidade.

A pesquisa possui a seguinte problematização: Em quais condições a contabilidade é realizada, em uma cidade de interior, onde o acesso a informações e tecnologias são ainda remotas?

O estudo realizado tem como foco a importância de diferentes aspectos, são eles:

1. Relevância das micro e pequenas empresas para o Brasil: As pequenas e médias empresas têm papel fundamental para alavancar o crescimento do País. Em maior número, os pequenos negócios são de fundamental importância no Brasil, pois são responsáveis pelo grande número de geração de emprego por ano.

2. A Importância e o desenvolvimento da profissão contábil: Considerado um dos principais profissionais atualmente, o Contador vem buscando cada vez mais o seu espaço. Responsável por informações econômicas e financeiras, o contador tem papel fundamental em um processo de decisão. Segundo Stephens (2011): “As modificações atuais que ocorrem nas demonstrações contábeis estão em linha com a realidade internacional do mundo dos negócios. As novas normas que disciplinam e regulamentam as atividades do contador, por meio da introdução das Normas Brasileiras de Contabilidade, Resoluções do Conselho Federal de Contabilidade e demais órgãos reguladores, estão ocorrendo em grande número."

A profissão contábil passou a ganhar mais prestígio a partir dos anos 90 no Brasil, sendo hoje, um dos cursos acadêmicos mais procurados pelos estudantes, e até mesmo por profissionais atuantes em outras áreas. A sua importância no Brasil pode ser observada no estudo, bem como o surgimento, legislação, campo de atuação e perspectivas para o futuro do Contabilista. 
A partir de 2015 nao vai haver mais formação de técnico em contabilidade, a Lei n 12.249/2010 alterou o Art. 12 do Decreto-lei n9.295/1946, Acrescentando o parágrafo 20. “ os Técnicos em Contabilidade já registrados em Conselho Regional de Contabilidade e os que venham a fazê-lo até 2015 têm assegurado o seu direito ao exercício da Profissão", ou seja, após 2015 não vai mais ser realizada a prova de tecnico contábil.

1. Mudança legal: No Brasil, as Pequenas e Médias Empresas (MPEs) passaram a ter critérios de contabilidade específicos e diferenciados regido pelas Normas Brasileiras de Contabilidade (NBC) TG 1000 (ex NBC - T - 19.41). "O objetivo das Demonstrações Contábeis e Pequenas e Médias Empresas é oferecer informações sobre a posição financeira(balanço Patrimonial, o desempenho(resultado e resultado abrangente) e fluxos de caixa da entidade, que é útil para a tomada de decisão por vasta gama de usuários que não está em posição de exigir relatórios feitos sob medida para atender suas necessidades particulares de informação.( NBC TG 1000 - Conceitos e Princípios gerais).

2. A constante mudança nas leis, procedimentos e tudo que se relaciona com a contabilidade, demanda profissionais altamente atualizados, o mercado de trabalho está escasso de profissionais qualificados, criativos e capacitados. Hoje, mais do que nunca, é preciso a conscientização da importância da pesquisa em relação à construção do conhecimento. Para o ser humano ser criativo e conseguir solucionar todos os problemas encontrados no decorrer da vida profissional, é necessário que o mesmo esteja por dentro de todos os assuntos relativos à sua área de atuação, tenha bastante desenvoltura e inovação. "Aqueles profissionais que, hoje, ainda ficam presos ao passado e só conhecem, exclusivamente, a contabilidade, em termos de partidas dobradas, debitando e creditando sem agregar nenhum valor à empresa, estarão com seus dias condenados." (Cosenza; p. 61)

3. Importância do Nordeste no Brasil: Sendo o terceiro maior complexo regional do Brasil, ocupando $18,2 \%$ da área do país, a Região Nordeste possui nove estados e possui grande diversidade cultural, com elementos indígenas, dos escravos africanos, dos imigrantes europeus. É um dos complexos regionais mais ricos em manifestações culturais.

A economia da Região Nordeste do Brasil foi a base histórica do começo da economia do Brasil, já que as atividades em torno do pau-brasil e da cana-de-açúcar predominaram e foram iniciadas no Nordeste do Brasil. A Região Nordeste é, atualmente, a terceira economia do país entre as grandes regiões.

Uma micro empresa por mais simples que seja não deixa de ser uma organização empresarial pelo lugar que está, todas tem seu corpo diretivo, sua atividade operacional, seus consumidores. Por estar lá "tão longe" ao modo geográfico de ver, está apta e deve ter seus direitos e deveres contábeis conhecidos e cumpridos. Claro que no sertão nordestino, o acesso a tais informações pode não acontecer, pois as tecnologias muitas vezes demoram de chegar, o poder aquisitivo da maioria das pessoas é muito menor. É importante, porém observar que a economia nordestina está em constante processo de desenvolvimento, sendo que a região tem recebido diversas indústrias, além da economia nordestina explorar petróleo, possuir o importante polos petroquímicos de Camaçari, na Bahia. A região possui ainda outras riquezas, como camarão, turismo e cana-de-açúcar. 
O trabalho considerou a hipótese de que há necessidade de formar profissionais para atender as regiões afastadas das grandes metrópoles no país e como estudo de caso foi analisada a cidade de Mortugaba no estado da Bahia, Região Nordeste do país.

O trabalho consiste em uma pesquisa dedutiva, que utiliza de pesquisa bibliográfica, relato histórico e estudo de caso, conforme definidos a seguir:

Portanto, o trabalho contém pesquisa bibliográfica, além de estudo de caso.

a. Para a realização do estudo de caso, serão realizados os seguintes procedimentos:Citar dados demográficos da região e os números relativos ás empresas

b. Número de faculdades na região e na Bahia

c. Entrevista há 2 empresários da região para saber como eles atendem aspectos contábeis e legais e como selecionam e contratam contadores, considerada duas análises para exemplo.

Nas considerações finais destaca-se a necessidade de investimentos em cursos e apoio do governo federal para abertura de cursos superiores de qualidade, para garantir a sustentabilidade.

\section{A PROFISSÃO DO CONTADOR NO BRASIL}

\subsection{O PERFIL}

A presença do contabilista é cada vez mais necessária para a sociedade e para as organizações, sejam elas de finalidade lucrativa ou não.

O profissional contábil necessita de aprendizagem contínua e atualização. O contador é o responsável por fornecer informações a administração da organização para a tomada de decisões, assim como alertar sobre os riscos e oportunidades de cada escolha, e se ainda houver, fornecer possíveis soluções para os problemas que foram apresentados. O contabilista registra, quantifica, projeta, analisa, avalia, orienta e produz elementos cuja essência depende dos organismos econômicos, administrativos e financeiros.

Iudícibus e Marion (2006, p.43) afirmam que:"Diante de um leque diversificado de atividades, podemos dizer que a tarefa básica do contador é produzir e/ou gerenciar informações úteis aos usuários da Contabilidade para a tomada de decisões. Ressalta-se, entretanto, que, em nosso país, em alguns segmentos da nossa economia, principalmente na pequena empresa, a função do contador foi distorcida (infelizmente), estando voltada quase que exclusivamente para satisfazer as exigências do Fisco.

Com a necessidade constante de atualização, a tarefa básica do Contador fica com a função de produzir ou gerenciar informações aos usuários de Contabilidade para a tomada de decisões. O Contador fornece informações sobre o patrimônio, informações essas de ordem econômica e financeira, que facilitam as tomadas de decisões, tanto por parte dos administradores ou proprietários como também por parte daqueles que pretendem investir na empresa. Esse é o atual perfil do contador e que está sujeito a evoluções a cada dia, já que acompanha as mudanças ocorridas no ambiente empresarial. Por isso, a atualização constante 
e o aprimoramento da formação do Contador são indispensáveis para o desempenho das suas funções.

\subsection{O MERCADO}

A área de atuação do profissional contábil é bastante ampla, oferecendo inúmeras alternativas de trabalho. Dentre algumas áreas, além da tradicional atuação na prática de escrituração contábil, destacam-se outras oportunidades citadas por Iudícibus e Marion, (2006, p.44) e Santos et all. (2006 p.98):

Perícia Contábil: - A perícia Judicial é motivada por uma questão jurídica, solicitada pela justiça. O contador fará uma verificação na exatidão dos registros contábeis e em outros aspectos. Ex: apuração de haveres, lucros cessantes, impugnações fiscais e avaliação de patrimônio líquido.

Auditoria: exame e emissão de pareceres sobre demonstrações financeiras, controles internos e gestão.

Fiscal: também chamada de consultoria contábil, é a fiscalização de contribuintes ou de contas de entes públicos.

Gestão de Empresas: administração de finanças, custos e fluxo de caixa e empreendimentos de qualquer porte.

Gestão Pública: atuação em áreas de planejamento, finanças, administração e contabilidade pública.

Atuarial: área estatística ligada a problemas relacionados com a teoria e o cálculo de seguros.

Consultoria: aos 3 setores da sociedade: iniciativa privada, governos e ONG's.

Ensino: atuação em dezenas de disciplinas como Contabilidade Rural, Contabilidade de Custos ou Orçamento Público. 


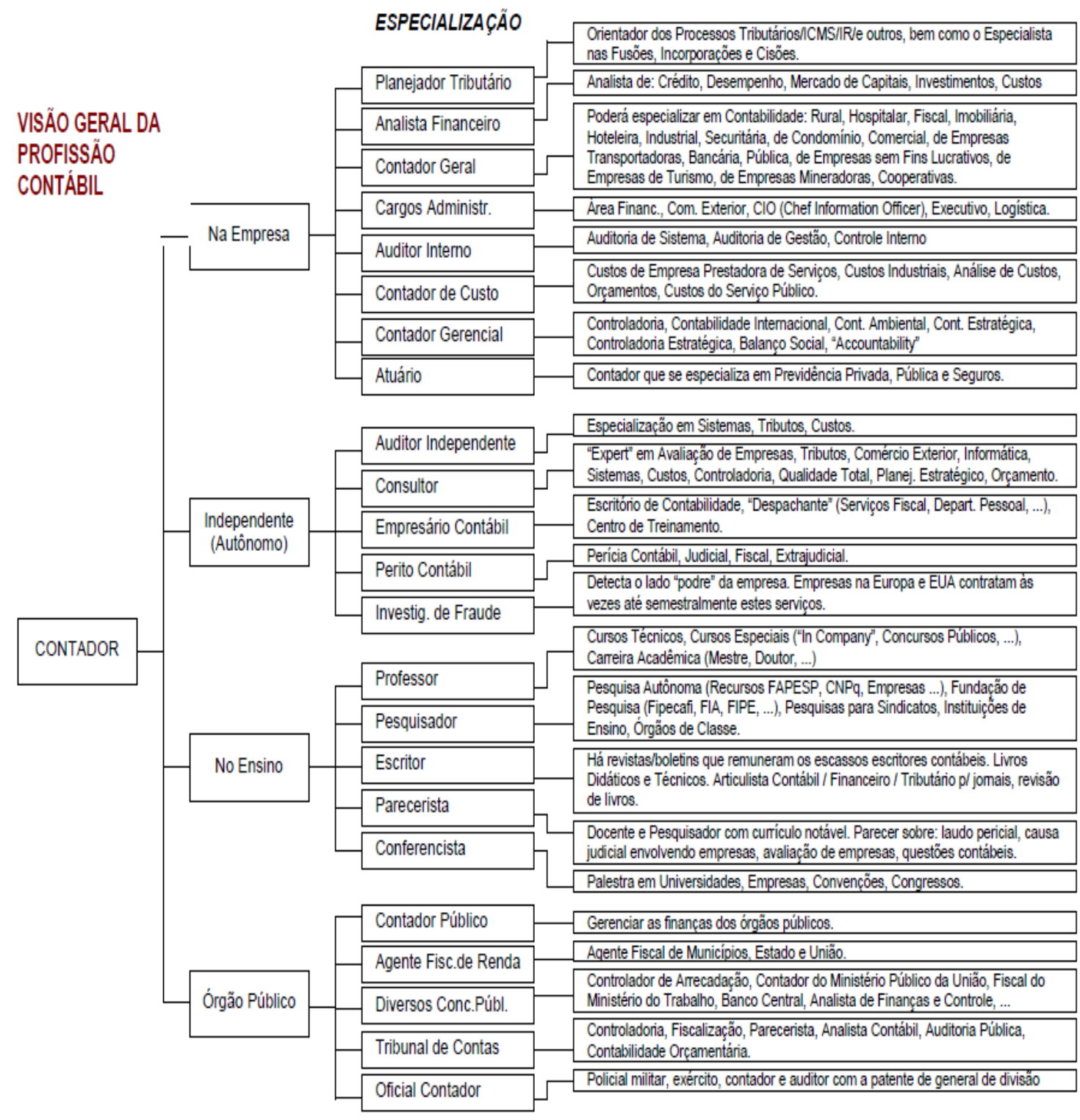

Figura 01: Fonte: Visão geral da profissão Contábil

Fonte: Iudícibus e Marion (2006) p.47

O contador atual deve procurar seguir as tendências exigidas na sua profissão, como falar mais de um idioma, conhecer a informática, além de possuir conhecimentos na área do Direito, Administração e Economia.

\subsection{DIRETRIZES CURRICULARES}

Para ser contador, é preciso ter formação Superior de ensino Contábil, Bacharel em Ciências Contábeis, conforme a legislação $\mathrm{n}^{\circ}$ 9.295, de 27 de maio de 1946 que define o exercício da profissão Contábil para o nível Técnico ou Graduação. 
Hoje vigoram as novas diretrizes instituídas pela Resolução CNE/CES 10, de 16 de dezembro de 2004, que institui as Diretrizes Curriculares Nacionais Para o curso de graduação em Ciências contábeis e dá outras Providências. Por essa resolução, as Instituições de Ensino Superior deverão estabelecer a organização curricular para os cursos de Ciências Contábeis por meio de Projeto Pedagógico, com descrição dos seguintes aspectos:

I. Perfil profissional esperado para o formando, em termos de competências e habilidades;

II. Componentes curriculares integrantes;

III. Sistemas de avaliação do estudante e do curso;

IV. Estagio curricular supervisionado;

V. Atividades complementares;

VI. Monografia, projeto de iniciação científica ou projeto de atividade - como Trabalho de Conclusão de Curso (TCC) - Como componente opcional da instituição;

VII. Regime acadêmico de oferta;

VIII. Outros aspectos que tornem que tornem consistente o referido Projeto; capacitado a:

No Art $3^{\circ}$ são abordadas as condições necessárias para que o futuro contador seja

I. compreender as questões científicas, técnicas, sociais, econômicas e financeiras, em âmbito nacional e internacional e nos diferentes modelos de organização;

II. apresentar pleno domínio das responsabilidades funcionais envolvendo apurações, auditorias, perícias, arbitragens, noções de atividades atuariais e de quantificações de informações financeiras, patrimoniais e governamentais, com a plena utilização de inovações tecnológicas;

III. revelar capacidade crítico-analítica de avaliação, quanto às implicações organizacionais com o advento da tecnologia da informação.

\subsection{COMPETÊNCIAS E HABILIDADES}

Conforme a Resolução CNE/CES 10, de Dezembro de 2004, Art. $4^{\circ}$ - O curso de graduação em Ciências Contábeis deve possibilitar formação profissional que revele, pelo menos, as seguintes competências e habilidades:

I. utilizar adequadamente a terminologia e a linguagem das Ciências Contábeis e Atuariais;

II. demonstrar visão sistêmica e interdisciplinar da atividade contábil;

III. elaborar pareceres e relatórios que contribuam para o desempenho eficiente e eficaz de seus usuários, quaisquer que sejam os modelos organizacionais;

IV. aplicar adequadamente a legislação inerente às funções contábeis; 
V. desenvolver, com motivação e através de permanente articulação, a liderança entre equipes multidisciplinares para a captação de insumos necessários aos controles técnicos, à geração e disseminação de informações contábeis, com reconhecido nível de precisão;

VI. exercer suas responsabilidades com o expressivo domínio das funções contábeis, incluindo noções de atividades atuariais e de quantificações de informações financeiras,, patrimoniais e governamentais, que viabilizem aos agentes econômicos e aos administradores de qualquer segmento produtivo ou institucional o pleno cumprimento de seus encargos quanto ao gerenciamento, aos controles e à prestação de contas de sua gestão perante à sociedade, gerando também informações para a tomada de decisão, organização de atitudes e construção de valores orientados para a cidadania;

Na economia globalizada, formar profissionais da área contábil, apenas com a visão de registrar os fatos contábeis ocorridos, é muito limitado, pois o profissional precisa buscar a interdisciplinaridade com diversas áreas. A contabilidade como ciência estruturada e com seu objeto de estudo delineado deve utilizar métodos e conceitos para alcançar resultados satisfatórios para as organizações, contribuindo para a evolução da sociedade de um modo geral. Nesse conceito, as instituições de ensino superior devem preocupar-se com o tipo de profissional que estão formando, pois na era da informação, do conhecimento e das novas tecnologias, para atender a demanda de profissionais, precisa-se de bons educadores.

\subsection{O EXERCÍCIO DA PROFISSÃO}

A atividade contábil não pode ser exercida por quem não é habilitado no estado de origem junto ao Conselho Regional de Contabilidade. A exemplo do Regulamento Geral dos Conselhos de Contabilidade quando determina que o exercício de qualquer atividade que exija a aplicação de conhecimentos de natureza contábil constitui prerrogativa dos Contadores e dos Técnicos em Contabilidade em situação regular perante o CRC. Para controle da qualidade do aprendizado dos profissionais, a Lei ${ }^{\circ} 12.249$ de 11 de junho de 2010, trouxe de volta o exame de suficiência para os profissionais. O contabilista deve ter sua assinatura e o número de registro no $\mathrm{CRC}$, em todo e qualquer trabalho realizado. Assim, os documentos contábeis só tem valor jurídico quando assinados e indicado o número de registro e da categoria.

\subsection{A CONDUTA}

Entre os deveres do contador para com a sociedade está a ética, que no caso da profissão, deve ser seguida pelo Código de Ética Profissional do Contabilista, aprovado pela Resolução CFC n 803-96, de 10.10.96, Para Lisboa (2007, p.137), "O código de ética é um instrumento que une a ética à lei. Embora tenha eficácia em nível corporativo, não elimina as oportunidades de fraude e crime de colarinho branco.". 
Na profissão não basta apenas possuir certificação. A conduta do profissional contábil é avaliada e deve contemplar qualidades como honestidade, competência, produtividade, sigilo, integridade, objetividade e sociabilidade. Os contadores devem sempre dizer a verdade e resistir às propostas que colocariam em risco a sua conduta legal. Isso aumenta ainda mais a relevância deste profissional no mercado.

\section{AS DEMONSTRAÇÕES CONTÁBEIS OBRIGATÓRIA SEGUNDO A NBC TG - 1000}

Aprovada pela resolução CFC No. 1.255/09, a NBC TG 1000 (ex NBC - T - 19.41) Contabilidade para Pequenas e Médias Empresas, entrou em vigor no dia $1^{\circ}$ de Janeiro de 2010, e passou a ser obrigatória em $1^{\circ}$ de janeiro de 2012.

Esta norma é destinada para as pequenas e médias empresas (PMEs), descritas:

Pequenas e médias empresas são empresas que:

(a) não têm obrigação pública de prestação de contas; e

(b) elaboram demonstrações contábeis para fins gerais para usuários externos.

Exemplos de usuários externos incluem proprietários que não estão envolvidos na administração do negócio, credores existentes e potenciais, e agências de avaliação de crédito. (CRC SP - NBC TG 1000)

A norma exige como e quais demonstrações contábeis que devem ser elaboradas pelas Pequenas e Médias empresas, no caso, Balanço Patrimonial, Demonstração do Resultado do Exercício (DRE), Demonstração do Resultado Abrangente (DRA), Demonstração das Mutações do Patrimônio Líquido (DMPL), Fluxo de Caixa e Notas Explicativas. No entanto, serão descritas também, algumas demonstrações que apesar de não serem obrigatórias, geralmente são usadas pelas empresas como ferramentas importantes na gestão. As demonstrações, portanto, são as seguintes:

\subsection{BALANÇO PATRIMONIAL}

Sendo uma das principais demonstrações contábeis, o Balanço Patrimonial serve para demonstrar a situação patrimonial e financeira das organizações em determinada data. Tal demonstração é composta pelo Ativo, Passivo e Patrimônio Líquido.

\subsection{DRE (DEMONSTRAÇÃO DE RESULTADO DO EXERCÍCIO)}

A DRE é a demonstração contábil apresentada de forma vertical e destinada a evidenciar a formação do resultado líquido do exercício, na composição de lucro ou prejuízo líquido. O resultado é obtido quando confrontado as receitas, custos e despesas apuradas, obedecendo o regime de competência.

Conforme Santos e Veiga (2012, p.57), a demonstração do Resultado do Exercício tem por objetivo apresentar e fornecer aos usuários das demonstrações financeiras, um resumo de 
todas as receitas e despesas e custos, de forma estruturada e ordenada verticalmente, o que proporciona uma visão objetiva dessas contas de resultado, que servirá de subsídio para a análise e tomada de decisão.

\subsection{DRA (DEMONSTRAÇÃO DO RESULTADO ABRANGENTE)}

A DRA é uma ferramenta de análise gerencial, pois, respeitando o princípio de competência de exercícios, atualiza o capital próprio dos sócios, por meio do registro no patrimônio líquido (e não no resultado) das receitas e despesas incorridas, porém de realização financeira "incerta", uma vez que decorrem de investimentos de longo prazo, sem data prevista de resgate ou outra forma de alienação. Na prática, visa apresentar os ajustes efetuados no Patrimônio líquido.

A forma de cálculo definida pelo CPC 26, estabelece que DRA seja elaborada a partir do Lucro Líquido apurado na DRE. E deve conter no mínimo as seguintes rubricas: o resultado líquido do período, cada item dos outros resultados abrangentes classificados conforme sua natureza, a parcela dos outros resultados abrangentes de empresas investidas reconhecida por meio do método de equivalência patrimonial e resultado abrangente do período.

As demais variações do patrimônio líquido (realização de reserva de reavaliação, enquanto houver saldo; certos ajustes de instrumentos financeiros; variações cambiais de investimento no interior e outros), que poderão transitar no futuro pelo resultado do período ou irem direto para lucros ou prejuízos acumulados, são apresentadas como Outros Resultados Abrangentes, dentro da Demonstração do Resultado Abrangente do Período.

\subsection{DMPL (DEMONSTRAÇÃO DAS MUTAÇÕES DO PATRIMÔNIO LÍQUIDO) E DLPA (DEMONSTRAÇÃO DOS LUCROS E PREJUÍZOS ACUMULADOS)}

A DMPL é uma demonstração que evidencia as movimentações nas contas do patrimônio líquido durante determinado período. É obrigatória para companhias abertas, sendo facultativa para as demais. Por ser uma demonstração mais completa, desobriga a apresentação da DLPA.

Consiste em uma demonstração significativa para a elaboração do fluxo de caixa, mas também é de grande interesse de investidores, também em situações de fusão, aquisição ou venda da empresa.

Na legislação vigente, não há nenhum modelo específico de DMPL, cada empresa pode criar o seu e adequar em acordo com a sua movimentação, respeitando que deve apresentar toda a mutação ocorrida no Patrimônio Líquido. 


\subsection{DFC(DEMONSTRAÇÃO DOS FLUXOS DE CAIXA)}

A DFC é um relatório contábil que indica as movimentações de entrada e saída de dinheiro no caixa em determinado período. É uma ferramenta importante de análise da capacidade da entidade de gerar caixa e equivalentes de caixa. investimentos.

A DFC se divide em três atividades: Operacionais, de financiamentos e de

Pode ser elaborada pelo método direto ou indireto. No direto, possibilita melhor planejamento financeiro, por ser mais detalhado. São demonstrados todos os pagamentos (saídas) e recebimentos(entradas) de cada atividade que contribuíram para a movimentação operacional das disponibilidades, no indireto, é apresentada a situação econômica em que todas as movimentações passíveis de mensuração são registrados, nele, é analisado os itens não circulantes para chegar a alteração dos circulantes.

\subsection{NOTAS EXPLICATIVAS}

As Notas Explicativas vêm para complementar as demonstrações contábeis. Pela lei, são necessárias no mínimo dez notas, mas nesse mínimo deve-se divulgar informações sobre a base de preparação das demonstrações financeiras e das práticas contábeis aplicadas. Conforme o CRC - PR, as notas explicativas devem:

\footnotetext{
I) apresentar informações acerca das bases de elaboração das demonstrações contábeis e das práticas contábeis específicas utilizadas;

II) divulgar as informações relevantes que não tenham sido apresentadas em outras partes das demonstrações contábeis;

III) prover informações que não tenham sido apresentadas em outras partes das demonstrações contábeis, mas que sejam relevantes para compreendê-las.

A entidade deve indicar em cada item das demonstrações contábeis a referência com a respectiva informação nas notas explicativas.
}

Com a harmonização contábil internacional e com o desenvolvimento de novas tecnologias e sistemas, muitas empresas mudaram suas formas de contabilização, alem de aumentar a complexidade da contabilidade. Este fato tornou as notas explicativas ainda mais relevante para as empresas.

\section{DEMONSTRAÇÕES CONTÁBEIS NÃO OBRIGATÓRIAS, MAS RELEVANTES PARA A GESTÃO E PARA TOMADA DE DECISÃO}

Com a necessidade dos empresários tomarem decisões, com o aumento da competitividade e com a cobrança social, inclusive externa, da prestação de contas das instituições em relação à sustentabilidade econômica, social e ambiental, alguns demonstrativos contábeis se tornaram muito relevantes para as pequenas e médias empresas, ainda que não obrigatórios. A seguir apresenta-se alguns deles: 


\subsection{DVA (DEMONSTRAÇÃO DO VALOR ADICIONADO)}

O principal papel da DVA é informar o valor da riqueza criada pela organização e a forma de sua distribuição. Ainda, apresenta como características, refletir na prática o conceito econômico do PIB e destacar a importância dos fatores de produção: remuneração do trabalho, arrecadação ao governo (tributos), remuneração do capital (juros), remuneração do capital do acionista (lucros). Apesar de não obrigatória, é muito relevante para demonstrar o investimento ou o gasto do recursos e este instrumentos demonstra a sustentabilidade e a relação da empresa com a sociedade.

\subsection{BALANÇO SOCIAL E OUTROS DEMONSTRATIVOS PARA INFORMAÇÃO DE NATUREZA SOCIAL E AMBIENTAL}

Dentro deste processo de uso de recursos, as empresas produzem novas riquezas e bens destinados ao consumo e à satisfação das necessidades da própria sociedade. Além disso, em muitas circunstâncias investem em ações voltadas aos seus colaboradores e à sociedade onde atuam, investimentos estes que podem ser evidenciados por meio do Balanço Social ou outros demonstrativos como Relatório Social, Relatório Social, Demonstrativo regulamentado pela NBC T-15 (Norma Brasileira de Contabilidade 15) e Relatório Integrado.

\subsection{PLANO DE NEGÓCIO}

Antes usado apenas para atender requisitos na busca de capital, hoje a elaboração de um Plano de Negócio é fundamental para o empreendedor, não somente para a busca de recursos mas, principalmente, como forma de sistematizar suas ideias e planejar de forma mais eficiente, antes de entrar de cabeça em um mercado sempre competitivo. Segundo o SEBRAE (2012), o plano de negócios é um documento formal que contém informações sobre o conceito do negócio, os riscos, os concorrentes, o perfil da clientela, as estratégias de marketing, bem como todo o plano financeiro que viabilizará o novo negócio. (SEBRAE, 2012).

Este instrumento pode ser usado para gestão, para prestação de contas para sócios ou investidores ou para projeções de negócios.

Um Plano de Negócios direciona tudo que há na empresa, sua ações presentes e futuras. Com ele é possível Avaliar riscos e identificar soluções, definir os pontos fracos e fortes da empresa em relação aos concorrentes, conhecer as vantagens competitivas da empresa, identificar o que agrega valor para o cliente, planejar e implantar uma estratégia de marketing, avaliar investimentos, identificar as necessidades de absorção de novas tecnologias e novos processos de fabricação e calcular o retorno sobre o capital investido.

\section{ESTUDO DE CASO SOBRE MORTUGABA, CIDADE DO INTERIOR DA BAHIA.}

Neste tópico foi abordado o estudo de caso em uma cidade do interior da Bahia.

Saber até que ponto a contabilidade é conhecida e usada pelas micro e pequenas empresas é um fator que põe em dúvida a importância dada para a contabilidade e suas leis no 
Brasil. Nas capitais e grandes cidades é mais fácil o acesso a tais procedimentos, e ainda assim, muitas vezes são deixados de lado por falta de informação ou por outro motivo qualquer.

Mortugaba, a cidade pesquisada, localiza-se no interior da Bahia, há $743 \mathrm{~km}$ de Salvador e possui uma população aproximada de 15 mil habitantes, apesar de ser a mais nova da região, com 50 anos, elas se sobressai, sendo que sua economia destaca-se pela agropecuária e pelo comercio, um dos mais desenvolvidos da região. A região possui faculdade com metodologia a distância em alguns cursos como Administração, Letras, Biologia, Geografia, Psicologia e outros; e na cidade recentemente está formando técnicos contábeis. No entanto, a graduação em Ciências Contábeis está na cidade de maior porte mais próxima, que é Vitória da Conquista há $196 \mathrm{~km}$, sendo $51 \mathrm{~km}$ estrada de terra.

O município possui dois escritórios de Contabilidade, sendo que um deles é de um Contador formado recentemente, e que aos poucos busca seu espaço na região. O outro escritório, tem como clientes a maioria do comercio Mortugabense que usa a Contabilidade, dentre ele os maiores empresários da região, é de responsabilidade de um técnico contábil, e quem assina o escritório são Contadores de Vitória da Conquista, já citada anteriormente.

A maioria do comércio é informal pela dificuldade de contabilização e falta de conhecimento e acesso a tecnologia e informação.

\subsection{A PESQUISA}

Não foi realizada uma significtiva, por não dispor de uma estrutura grande, mas, para a pesquisa foram entrevistadas duas empresas de pequeno porte da cidade, todas do ramo alimentício. Foi realizada por meio de um questionário com 10 perguntas abertas e 4 fechadas, que foi respondido pelos responsáveis pelas empresas. As empresas selecionadas foram: 1-Supermercado e padaria; 2-Supermercado.

Os gestores das empresas entrevistadas foram:

Estabelecimento 1: Supermercado e Padaria: Fundada em 1986, iniciou suas atividades no ramo de padaria. Com o crescimento dos negócios foi incluída novas atividades econômicas procurando adéqua-se as necessidades dos clientes. Hoje atua no ramo de Comercio de produtos de Panificação Varejista de Mercadorias em Geral com predominância de produtos alimentícios. Administrada pelo proprietário.

Estabelecimento 2: Supermercado: Iniciou em fevereiro de 2005 apenas com um funcionário e poucos recursos, hoje é uma empresa que atua no Comércio varejista de mercadorias em geral, com predominância de produtos alimentícios, minimercados, mercearias e armazéns. Administrada pelo proprietário.

A seguir, serão demonstrados os resultados obtidos com o questionário, serão abordadas pergunta a pergunta com as respectivas respostas. 


\begin{tabular}{|c|c|}
\hline Perguntas & Respostas \\
\hline \multirow[t]{2}{*}{ 1. Número de clientes que possui? } & Estabelecimento 1: 5.000 \\
\hline & Estabelecimento 2: 1.000 \\
\hline \multirow[t]{2}{*}{ 2. A contabilidade da empresa é própria(interna) ou terceirizada? } & Estabelecimento 1: Terceirizada \\
\hline & Estabelecimento 2: Terceirizada \\
\hline \multirow[t]{2}{*}{ 3. O profissional é de onde? } & Estabelecimento 1: Mortugaba \\
\hline & Estabelecimento 2: Mortugaba \\
\hline \multirow{2}{*}{$\begin{array}{l}\text { 4. Na empresa já foi realizada alguma auditoria? Se sim, explique os } \\
\text { motivos que levaram a tal decisão. }\end{array}$} & Estabelecimento 1: Não \\
\hline & Estabelecimento 2: Não \\
\hline 5. Para que serve a contabilidade dentro da empresa? & Estabelecimento 1: a, b, c \\
\hline a) Cumprimento da Lei & Estabelecimento 2: a \\
\hline b) Método de na forma legal, pagar menos tributo & \\
\hline c) Tomar decisões & \\
\hline d) Acompanhar o orçamento & \\
\hline \multirow{2}{*}{$\begin{array}{l}\text { 6. Os dados contábeis são utilizados como ferramenta para tomada de } \\
\text { decisão? }\end{array}$} & Estabelecimento 1: Sim \\
\hline & Estabelecimento 2: Não \\
\hline 7. Como é o seu contato, com a contabilidade da empresa? & Estabelecimento 1: e \\
\hline a) Não conhece o profissional responsável & Estabelecimento 2: d \\
\hline b) Conhece o profissional responsável, mas não sabe como é o seu & \\
\hline trabalho. & \\
\hline c) Conhece o trabalho, mas,normalmente não tem contato & \\
\hline d) Tem contato, mas raramente utiliza os seu trabalho para a tomada de & \\
\hline decisão e acompanhamento da empresa & \\
\hline e) Tem contato e com habitualidade utiliza suas informações para a & \\
\hline $\begin{array}{l}\text { f) Utiliza muito as informações para decisão e acompanhamento da } \\
\text { empresa }\end{array}$ & \\
\hline \multirow{2}{*}{$\begin{array}{l}\text { 8. O Sistema de Informação usado na empresa foi introduzido de forma } \\
\text { própria ou pelo contador? }\end{array}$} & Estabelecimento 1: Ambas as partes \\
\hline & Estabelecimente 2. Pelo contador \\
\hline \multirow{2}{*}{ 9. Há alguma informação que precisa e não possui com a } & Estabelecimento 1: Sim. \\
\hline & Estabelecimento 2: Muitas. \\
\hline \multirow{12}{*}{$\begin{array}{l}\text { 10. Assinale abaixo as demonstrações contábeis que conhece e utiliza } \\
\text { na sua empresa: } \\
\text { a) Balanço Patrimonial } \\
\text { b) DRE - Demonstração do Resultado do Exercício } \\
\text { c) DRA - Demonstração do Resultado Abrangente } \\
\text { d) Plano de Negócio } \\
\text { e) Demonstrações de Mutações do Patrimônio Líquido (DMPL) ou de } \\
\text { Lucros ou Prejuízos Acumulados (DLPA) } \\
\text { f) Demonstração das Origens e Aplicações de Recursos - DOAR } \\
\text { g) Demonstração dos Fluxos de Caixa - DFC } \\
\text { h) Demonstração do Valor Adicionado - DVA } \\
\text { i) Balanço Social } \\
\text { j) Notas Explicativas }\end{array}$} & Estabelecimento 1:: A, B, G \\
\hline & Estabelecimento 2: Desconhece \\
\hline & \\
\hline & \\
\hline & \\
\hline & \\
\hline & \\
\hline & \\
\hline & \\
\hline & \\
\hline & \\
\hline & \\
\hline \multirow{3}{*}{$\begin{array}{l}\text { 11. Conhece o CPC - PME ou a NBC TG } 1000 \text { que aborda a } \\
\text { Contabilidade para pequenas e Média Empresas? }\end{array}$} & Estabelecimento 1: Não. \\
\hline & \\
\hline & Estabelecimento 2: Desconhece \\
\hline \multirow{3}{*}{$\begin{array}{l}\text { 12. Quais mudanças ou contribuições espera no futuro que ocorra com } \\
\text { a Contabilidade na sua empresa? }\end{array}$} & Estabelecimento 1: As dificuldades que encontramos no dia a dia, \\
\hline & $\begin{array}{l}\text { acreditamos que podemos minimizá-las se no futuro ter dentro da empresa } \\
\text { um contador que nos ajude a tomar decisões e aperfeiçoar todo o } \\
\text { funcionamento administrativo da empresa. }\end{array}$ \\
\hline & $\begin{array}{l}\text { Estabelecimento 2: Espero que a contabilidade esteja mais presente em } \\
\text { nossas empresas, orientando-nos e passando mais segurança para a } \\
\text { pequena e micro empresa estimulando o crescimento do empreendedor. } \\
\text { Por que não basta calcular impostos e enviar notas todo final de mês, é } \\
\text { ainda muito inseguro da forma que faz. }\end{array}$ \\
\hline
\end{tabular}

Quadro 01: Questionário de Pesquisa

Fonte: dados da pesquisa. Elaborado pelos autores.

ENIAC Pesquisa, Guarulhos (SP), p. 77-95, v. 2, n. 2, jul.-dez. 2013. 
No caso específico abordado em Mortugaba, nota-se que a Contabilidade não é integrada à administração da empresa, e está um pouco distante o uso da mesma em todo processo de decisão.

Pode-se identificar que o estabelecimento 1 tem número maior de clientes do que o 2. As duas empresas optaram por não informar o seu volume de vendas. A contabilidade das duas empresas é terceirizada e o profissional é da própria cidade de Mortugaba. Apesar do estabelecimento 1 demonstrar possuir mais informações sobre a Contabilidade do que o estabelecimento 2, ambos carecem de informações necessárias e acreditam que para o futuro a contabilidade é peça chave para o crescimento das mesmas a médio e longo prazo.

\section{CONCLUSÕES}

Apesar da pesquisa ser um ensaio, portanto não amostral, após ver as duas situações exemplo no estudo de caso, pode-se ter uma breve visão de como a Contabilidade é conhecida e tratada pelos micro e pequenos empresários em Mortugaba e região. As dificuldades geográficas, regionais e culturais também são responsáveis por tal fato.

De um modo geral, as duas empresas pesquisadas, não têm o conhecimento necessário da legislação ou até mesmo das demonstrações contábeis necessárias para o uso em uma micro empresa ou empresa de pequeno porte. Tal fato deve acontecer em muitas outras micro empresas e empresas de pequeno porte no Brasil

O desenvolvimento da Contabilidade não pode ficar concentrado nas grandes cidades e capitais, o Brasil é imenso e o seu desenvolvimento econômico precisa ser de Norte a Sul. Bons profissionais em um momento de crescimento são o que faz grande diferença.

Diante de tal dificuldade, nota-se a necessidade para o Governo Federal repensar políticas públicas de estruturação trazendo novas formas de capacitação e formação para futuros contadores. Sendo esse um possível passo inicial para a implantação da TG $1.000 \mathrm{em}$ todo o País

Portanto, considera-se os seguintes aspectos:

O Brasil, por meio de um trabalho do Conselho Federal de Contabilidade, em conjunto com os Conselhos Regionais de Contabilidade e outros órgãos da classe contábil tem um relevante papel normativo e de fiscalização no país. Este papel, entre outras funções desempenhadas, contempla uma busca contínua para harmonização internacional, inclusive de micro e pequenas empresas. Tais ações são muito relevantes para a transparência e aumento de competitividade das empresas, reduzindo desigualdades sociais, possibilitando sustentabilidade e desenvolvimento regional, facilitando transacionais internacionais e captação de recursos.

Apenas a normatização e fiscalização não são suficientes para o desenvolvimento de uma região, é necessário investimento e políticas públicas para incentivo e oferta de cursos superiores de qualidade em diversas regiões do país. 
Certamente, a realidade de Mortugaba consiste na realidade de muitas regiões brasileiras, logo é necessário desenvolver tais políticas.

A Contabilidade e as suas inovações são fundamentais para o desenvolvimento sustentável, portanto, elas tem um papel fundamental para o país.

\section{REFERÊNCIAS}

BIFI, Claudio Rafael; RIBEIRO, Eduardo Franco; SANTOS, Marcia da Silva; SILVA, Mauricio Fernando da; MELO, Paulo da Silva. Introdução a Contabilidade: Noções Fundamentais. São Paulo: Saraiva, 2007.

BRAGA, Hugo Roch. Demonstrações Contábeis: Estrutura, Análise e Interpretação. São Paulo: Atlas, 1999.

BRASIL. Lei $n^{\circ}$ 6.404, de 15/15/1976, dispõe sobre as sociedades por ações.

.Lei $\mathrm{n}^{\mathrm{o}} 11.638$, de 28/12/2007, dispõe sobre as sociedades por ações.

.Lei no 11.941 , de 27/5/2009, altera a legislação tributária federal.

BRASIL. Conselho Nacional De Educação. Câmara De Educação Superior. Resolução CNE/CES 10, De 16 De Dezembro De 2004.

CARVALHO, Ronaldo Froés de. Currículo de Ciências Contábeis :Desafios Para Adoção Ao Novo Modelo Contábil Brasileiro. Doutorado em educação. São Paulo: PUC SP, 2010.

CFC - Conselho Federal de Contabilidade. Legislação da Profissão Contábil. São Paulo:

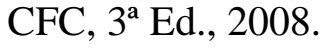

CFC - Conselho Federal de Contabilidade. Mensagem a um Futuro Contabilista. São Paulo, $3^{\text {a }}$ Ed., 1997.

CFC - Conselho Federal de Contabilidade. Resolução CFC 1255. Normas internacionais de relatórios financeiros para pequenas e médias empresas - IFRS - PME (NBC TG 1.000). Brasília: CFC, 2009.

CPC - COMITÊ DE PRONUNCIAMENTOS CONTÁBEIS. CPC 26.

http://www.cpc.org.br/pdf/CPC26_R1.pdf. Acesso em 12 de Agosto de 1012.

CRC - PR - Conselho Regional de contabilidade do paraná. Demonstrações Contábeis: Aspectos Práticos - Elaboração e Apresentação conceitual de acordo com o IFRS. http://www.crcpr.org.br/new/content/download/2011_demonstracoesContabeis.pdf. Acesso em 17 de Julho de 2012.

CRC - SP - Conselho Regional de contabilidade de são paulo. Manuais PMES 
http://www.crcsp.org.br/portal_novo/publicacoes/manuais_pmes/conteudo/sup_3.pdf. Acesso em 05 de Agosto de 2012.

CHING, Hong Yuh; MARQUES, Fernando; PRADO, Luciene. Contabilidade e Finanças: para não especialistas. São Paulo: ABDR, 2003.

COSENZA, José Paulo. Perspectivas para a profissão contábil num mundo globalizado "Um estudo a partir da experiência brasileira". Revista Brasileira de contabilidade. Brasília, Conselho Federal de Contabilidade. A XXX, nº 13 jul./ago. 2001, p. 43-63.

GIL, Antonio Carlos. Como Elaborar Projetos De Pesquisa. 4a edição. São Paulo: Atlas, 2007.

IUDÍCIBUS, Sergio de. Teoria da Contabilidade. $7^{a}$ edição. São Paulo: Atlas, 2004.

IÚDÍCIBUS, Sergio de; MARION, José Carlos. Introdução à Teoria da Contabilidade: Para o nível de Graduação. São Paulo, Atlas, 2006.

LAKATOS, Eva Maria e MARCONDI, Marina de Andrade. Metodologia Do Trabalho Científico: procedimentos básicos, pesquisa bibliográfica, projeto e relatório e publicações e trabalhos científicos. São Paulo, Atlas, 2007.

LISBOA, Lázaro Plácido. Ética Geral e Profissional em Contabilidade. orientações. Fipecafi $2^{a}$ Edição. São Paulo, atlas, 2007.

LOPES, Jorge.; FILHO, José Francisco Ribeiro; PEDERNEIRAS, Marcleide. Educação Contábil: Tópicos de Ensino e Pesquisa. São Paulo, Atlas, 2008.

MARION, José Carlos. Contabilidade Empresarial. São Paulo, Atlas, 2009.

PEREZ JR., José Hernandez; BENGALLI, Glaucos Antonio. Elaboração das Demonstrações Contábeis. São Paulo, Atlas, 1999.

QUINTANA, Alexandre Costa; SERAFIN, Annelise da Cruz; SAURIN, Valter. Revista de Ciências da Administração - $\quad$ v.5, $\quad$ n.10, $\quad$ jul/dez $2003 \quad 4$ dialnet.unirioja.es/descarga/articulo/4013984.pdf. Acesso em 17 de Outubro de 2012.

SANTOS, Fernando de Almeida e VEIGA, Windsor Espenser. Contabilidade com Ênfase em Micros e Pequenas Empresas. (11.638/07, 11.941/09 e NBC TG 1.000/CPC-PME). São Paulo: Atlas, 2012.

SANTOS, José Luiz dos; SCHIMDT, Paulo; GOMES, José Mário Matsumura; FERNANDES, Luciane Alves. Introdução à Contabilidade: Atualizada pela Minirreforma tributária Lei ${ }^{\circ} 10.637 / 02.2006$.

SCHMIDT, Paulo; Santos, José Luiz dos. História da Contabilidade: Foco Na Evolução Das Escolas Do Pensamento Contábil. São Paulo, Atlas, 2008.

SEBRAE SP - Serviço Brasileiro de Apoio às micro e Pequenas Empresas. Produtos e Serviços. 
http://www.sebraesp.com.br/TenhoUmaEmpresa/ProdutoseServicos/ViaInternet/PlanoDeNeg ociosSPPLAN/Paginas/SP-Plan.aspx. Acesso em 17 de Agosto de 2012.

SILVA, Antonio Carlos Ribeiro Da. Metodologia De Pesquisa Aplicada A Contabilidade: orientações, estudos, projetos, artigos, relatórios, monografias, dissertações, teses. $2^{\text {a }}$ Edição. São Paulo, Atlas, 2006.

STEPHENS, Moore. O novo Cenário da Profissão de Contador. 2011. http://msbrasil.com.br/blog/contabilidade/o-novo-cenario-da-profissao-de-contador/.Acesso em $11 / 06 / 12$. 